\title{
Evaluation of the Use of Recycled Vegetable Oil as a Collector Reagent in the Flotation of Copper Sulfide Minerals Using Seawater
}

\author{
Felipe Arcos and Lina Uribe *
}

Citation: Arcos, F.; Uribe, L.

Evaluation of the Use of Recycled Vegetable Oil as a Collector Reagent in the Flotation of Copper Sulfide Minerals Using Seawater. Recycling 2021, 6, 5. https://doi.org/ 10.3390/recycling6010005

Received: 14 December 2020

Accepted: 4 January 2021

Published: 11 January 2021

Publisher's Note: MDPI stays neutral with regard to jurisdictional clai$\mathrm{ms}$ in published maps and institutional affiliations.

Copyright: (C) 2021 by the authors. Licensee MDPI, Basel, Switzerland. This article is an open access article distributed under the terms and conditions of the Creative Commons Attribution (CC BY) license (https:// creativecommons.org/licenses/by/ $4.0 /)$.
School of Mining Engineering, University of Talca, Talca 3460000, Chile; farcos14@alumnos.utalca.cl

* Correspondence: luribe@utalca.cl; Tel.: +56-220-1798

\begin{abstract}
Considering sustainable mining, the use of seawater in mineral processing to replace conventional water is an attractive alternative, especially in cases where this resource is limited. However, the use of this aqueous medium generates a series of challenges; specifically, in the seawater flotation process, it is necessary to adapt traditional reagents to the aqueous medium or to propose new reagents that achieve better performance and are environmentally friendly. In this research, the technical feasibility of using recycled vegetable oil (RVO) as a collector of copper sulfide minerals in the flotation process using seawater was studied. The study considered the analysis of the metallurgical indexes when different concentrations of collector and foaming reagent were used, considering as collectors the RVO, potassium amyl xanthate (PAX) and mixtures of these, in addition to the methyl isobutyl carbinol (MIBC) as foaming agent. In addition, it was evidenced that the best metallurgical indexes were achieved using $40 \mathrm{~g} / \mathrm{t}$ of RVO and $15 \mathrm{~g} / \mathrm{t}$ of MIBC, which corresponded to an enrichment ratio of 6.29 , a concentration ratio of 7.01 , a copper recovery of $90.06 \%$ and a selectivity index with respect to pyrite of 4.03 and with respect to silica of 12.89 . Finally, in relation to the study of the RVO and PAX collector mixtures, it was found that a mixture of $60 \mathrm{~g} / \mathrm{t}$ of $\mathrm{RVO}$ and $40 \mathrm{~g} / \mathrm{t}$ of PAX in the absence of foaming agent presented the best results in terms of copper recovery (98.66\%) and the selectivity index with respect to pyrite (2.88) and silica (14.65), improving PAX selectivity and recovery compared to the use of RVO as the only collector. According to these results, it is possible to conclude that the addition of RVO improved the selectivity in the rougher flotation for copper sulfides in seawater. This could be an interesting opportunity for the industry to minimize the costs of the flotation process and generate a lower environmental impact.
\end{abstract}

Keywords: flotation; seawater; collectors; vegetable oil; recycled vegetable oil

\section{Introduction}

Froth flotation is one of the most widely used physicochemical methods of concentrating minerals in the mining industry today because of the high capacity and efficiency it offers in the process of obtaining metals [1]. Separation of minerals by froth flotation techniques depends primarily on the differences in the wettability of particles. The most important reagents used are the collectors, which selectively adsorb onto the surface of the mineral particles, making them hydrophobic and facilitating their adhesion to gas bubbles injected into the process that rise through the slurry to form a concentrate rich in the mineral of interest [2].

Among the different collectors currently available in the copper mining industry, the xanthates are widely used in the flotation of minerals such as common sulfides $(\mathrm{Cu}, \mathrm{Mo}, \mathrm{Pb}$, $\mathrm{Zn}, \mathrm{Co}$ and $\mathrm{Ni}$ ) and native metals $(\mathrm{Cu}, \mathrm{Ag}$, $\mathrm{Au}$, etc.). The xanthates are ionic collectors and contain a hydrophilic polar group (affinity with water) attached to a chain of hydrocarbons that turns out to be the hydrophobic part. Due to their strong ionic powers, xanthates have negative effects to the biota and health hazards to human and animals [3-5], and they become a major problem at the time of handling and disposal of the waste generated by 
the flotation [6]. It was estimated that a total of 52,000 tons of xanthates were consumed annually by the mining industry worldwide [7]. Most of the mining industry across the globe use xanthate. The efforts to reduce the harmful effects of these are focused on the search to develop a "green" collector, or environmentally friendly, that reduces or inhibits the generation of toxic substances.

On the other hand, because of the water scarcity in some mining areas around the world, some projects consider the use of seawater to process coper ores by flotation in countries such as Chile, Australia and Indonesia [8]. In Chile, Las Luces plant has been using sweater for their operations since 1994 [9], and more recently Esperanza mine from Antofagasta Minerals [10]. However, even though the use of seawater in mineral process can be seen as interesting alternative to solve the scarcity problems, its use in mineral processing leads to significant challenges such as corrosion in different equipment such as pipes, mills and flotation cells; and the reduction of the performance in the concentration process [11]. Within this framework, as possible solutions to these problems, it has been proposed to use some coatings of materials with high chemical and mechanical resistance [12], to use alloys of materials that better resist the corrosion phenomenon [13] and to study new operating conditions in the different processes associate, in order to achieve metallurgical recoveries and grades of copper without affecting the efficiency of by-products (Mo and $\mathrm{Au}$ ) [14].

Specifically, when seawater is used to carry out this concentration process, a series of problems is generated due to the high concentration of ions that it possesses $\left(\mathrm{Na}^{+}, \mathrm{K}^{+}\right.$, $\mathrm{Mg}^{2+}, \mathrm{Ca}^{2+}, \mathrm{SO}_{4}{ }^{2-}$ and $\mathrm{Cl}^{-}$). Mainly, there is the $\mathrm{pH}$ adjustment as seawater acts as a buffer solution, which generates a significant increase in lime consumption to achieve the $\mathrm{pH}$ values required in the process to depress pyrite [15]. Additionally, seawater generates a depressant effect on minerals such as molybdenite at $\mathrm{pH}$ values above 9.5. This is mainly due to the presence of calcium and magnesium cations in solution, which generates colloidal precipitates at $\mathrm{pH}$ levels above this value, preventing the recovery of this mineral [16]. It is because of these reasons that, new reagents are needed, in order to recover copper minerals (Chalcopyrite) in seawater, without affecting the recovery of secondary minerals, such as molybdenite. In addition, these new reagents must be able to depress pyrite to the $\mathrm{pH}$ of seawater.

In this sense, the use of vegetable oils could be an interesting alternative to replace and/or reduce the use of xanthates in copper sulfide ore flotation. There exists evidence that shows that the collecting properties of these oils can be competitive compared to the commercial collectors used in the sulfides flotation and native minerals [17-21]. Owusu et al. studied the use of commercial edible oils (canola, derived from rapeseed, and palm oil) as potential flotation reagents to add to the existing array of xanthates normally deployed for the selective flotation of copper sulfide minerals [18]. In addition, Bauer et al. [20] and Greene et al. [21] patented the use of various oils as collectors for the recovery of chalcopyrite and molybdenite from an ore containing $0.579 \% \mathrm{Cu}$ and $0.010 \%$ Mo. Furthermore, Benn et al. [22] proposed the use of rapeseed oil as a selective collector for galena $(\mathrm{PbS})$ recovery against pyrite. A laboratory flotation test using a complex sulfide ore containing $\mathrm{Pb}, \mathrm{Zn}, \mathrm{Cu}$ and Fe sulfides using $240 \mathrm{~g} / \mathrm{t}$ of rapeseed oil as collector gave a higher recovery of lead, copper and zinc minerals than when typical, conventional collectors (xanthate, dithiophosphate, mercaptan, etc.) were used. Pyrite recovery in this study was similar to that obtained using the conventional collectors.

Taking into account these considerations, this research proposes to study a recycled vegetable oil as a collector of copper sulfide minerals in the flotation process in seawater in order to contribute to reduce the toxic collector used in minerals processing and to find a different type of application of this waste This study considered the analysis of the metallurgical indexes when different concentrations of collector and foaming reagent were used, considering as collectors the RVO, potassium amyl xanthate (PAX) and mixtures of these, in addition to the methyl isobutyl carbinol (MIBC) as foaming agent. 


\section{Material and Methods}

\subsection{Mineral Sample}

The mineral sample used in this investigation was supplied by Minera Paicaví S.A. from the Chépica mine, located in the town of Pencahue, Chile. For the purposes of this work, each sample of $600 \mathrm{~g}$ of ore were crushed, ground in a ball mill and sieved to a P80 size of $212 \mu \mathrm{m}$, which corresponds to an appropriate size for rougher flotation.

Tables 1 and 2 present the results of the XRF and XRD analysis performed on the mineral sample. In the first one, it can be observed that, according to XRF analysis, the copper content was $2.20 \%$ and iron was $12.97 \%$, while, regarding its mineralogy, in the second table, it is observed that the content of these elements are mainly associated to chalcopyrite and pyrite and that gangue minerals are mainly quartz and phyllosilicates such as muscovite and chlorite.

Table 1. Results of the XRF analysis of the mineral sample.

\begin{tabular}{ccc}
\hline Element & Symbol & \% \\
\hline Silicon & $\mathrm{Si}$ & 41.00 \\
Sulfur & $\mathrm{S}$ & 23.60 \\
Potassium & $\mathrm{K}$ & 1.140 \\
Titanium & $\mathrm{Ti}$ & 0.031 \\
Vanadium & $\mathrm{V}$ & 0.011 \\
Chrome & $\mathrm{Cr}$ & 0.017 \\
Magnesium & $\mathrm{Mg}$ & 0.033 \\
Iron & $\mathrm{Fe}$ & 12.97 \\
Copper & $\mathrm{Cu}$ & 2.196 \\
Zinc & $\mathrm{Zn}$ & 0.307 \\
Arsenic & $\mathrm{As}$ & 0.008 \\
Silver & $\mathrm{Ag}$ & 0.003 \\
Platinum & $\mathrm{Pt}$ & 0.003 \\
Lead & $\mathrm{Pb}$ & 0.112 \\
Molybdenum & $\mathrm{Mo}$ & 0.002 \\
\hline
\end{tabular}

Table 2. Results of the XRD analysis of the mineral sample.

\begin{tabular}{ccc}
\hline Mineral Phase & Molecular Formula & $\%$ \\
\hline Quartz & $\mathrm{SiO}_{2}$ & 73.9 \\
Muscovite & $\mathrm{KAl}_{2}\left(\mathrm{Si}_{3} \mathrm{AlO}_{10}\right)(\mathrm{OH})_{2}$ & 5.5 \\
Chlorite & $(\mathrm{Mg}, \mathrm{Fe}++) 5 \mathrm{Al}_{(}\left(\mathrm{Si}_{3} \mathrm{Al}\right) \mathrm{O}_{10}(\mathrm{OH})_{8}$ & 1.9 \\
Pyrite & $\mathrm{FeS}_{2}$ & 13.0 \\
Chalcopyrite & $\mathrm{CuFeS}_{2}$ & 5.7 \\
\hline
\end{tabular}

\subsection{Chemical Reagents and Aqueous Media}

The collector reagents used in this research were potassium amyl xanthate (PAX) supplied by SOLVAY Chile and purified according the methodology described by Montalti et al. [23]. Sunflower recycled RVO was collected by Universidad de Talca and was previously filtered and was introduced in the flotation cell as supplied. The foaming agent used was methyl isobutyl carbonyl (MIBC Aerofroth 70 supplied by SOLVAY, Antofagasta, Chile). The only modifier considered in this project was lime $(\mathrm{CaO})$ to adjust the $\mathrm{pH}$ to 8 . MIBC was made down to $1 \mathrm{~mL} / \mathrm{L}$, by weighing $1 \mathrm{~g}$ into a clean $100 \mathrm{~mL}$ volumetric flask and making up to the mark with distilled water.

The supply of seawater used in this research was from the coast of the Maule region in Chile, specifically from the town of Iloca, highlighting that the water was extracted at a point far from the shore so that its chemical composition was not affected or physically contaminated. The collected seawater had a pH of 7.6 and salinity of $35 \mathrm{~g} / \mathrm{L}$. During the flotation stage, all experiments were done at room temperature of $20^{\circ} \mathrm{C}$. 


\subsection{Experimental Procedure}

\subsubsection{Reduction of Mineral Sample Size}

The first comminution process was performed in the jaw crusher in order to obtain a P80 size of $2000 \mu \mathrm{m}$. Then, a wet milling process was performed, for which $67 \%$ of solids by weight (using $600 \mathrm{~g}$ of ore sample and $300 \mathrm{~g}$ of water) ore slurry was prepared. A first addition of reagents was made during this stage, specifically of lime $(0.7 \mathrm{~g})$ to regulate the $\mathrm{pH}$ to the desired value $(\mathrm{pH}$ 8). In addition, to determine the optimum grinding time, kinetic tests were carried out beforehand, allowing the grinding time to be set at $50 \mathrm{~min}$.

\subsubsection{Flotation Test}

The flotation process was carried out in a Edemet cell of $1.5 \mathrm{~L}$ by adding a pulp containing $600 \mathrm{~g}$ of mineral and $1200 \mathrm{~g}$ of water, forming 33\% of solids by weight, maintaining a $\mathrm{pH} 8$, adding wash water after each palletization and dosing the collecting and foaming reagents according to the test to be carried out for the investigation. The reagents were added at the same time during conditioning stage, which lasted 5 min and was done at an agitation speed of $1100 \mathrm{rpm}$. At this stage, the $\mathrm{pH}$ value was also adjusted to the desired value by the addition of lime. Once this was achieved, the flotation stage took place, which lasted $16 \mathrm{~min}$ and was carried out at a stirring speed of $1000 \mathrm{rpm}$, injecting an airflow of $5 \mathrm{~L} / \mathrm{min}$ maintaining a manual palletization every $10 \mathrm{~s}$. All tests were done in duplicate with an average standard error of $5 \%$.

Finally, once each flotation test was completed, both the concentrate and the process tail were dried. First, an Edemet pressure filter was used to remove the excess water and then the samples obtained were dried inside the drying oven for approximately $24 \mathrm{~h}$ at a temperature of $100^{\circ} \mathrm{C}$. Subsequently, the corresponding analyses were carried out using $\mathrm{XRF}$ to determine the content of $\mathrm{Cu}, \mathrm{Fe}, \mathrm{S}$ and $\mathrm{Si}$ in each sample and finally to calculate the metallurgical indexes for each test.

Rougher flotation tests were performed by evaluating the dosages of RVO or PAX collector to 20, 40, 60, 80 and $100 \mathrm{~g} / \mathrm{t}$. After that, mixtures of RVO/PAX at 80/20, 60/40, $40 / 60$ and $20 / 80 \mathrm{~g} / \mathrm{t}$, respectively, were evaluated. Finally, to evaluate the effect of MIBC frother in the presence of RVO, the best dosages of collectors (PAX or RVO) or mixtures of them were kept constant, according to the metallurgical results, to evaluate the dosages of MIBC at concentration levels between 0 and $20 \mathrm{~g} / \mathrm{t}$.

\subsubsection{Calculations and Methods of Analysis Used}

\section{- Metallurgical Indexes}

The most important metallurgical indexes studied were the grade and the recovery of $\mathrm{Cu}$ and $\mathrm{Fe}$ in the concentrate, since these data provide an indication of the efficiency of the flotation. Similarly, enrichment ratio, selectivity indexes, concentration ratio and concentration yield were studied. Table 3 shows the formulas used to calculate these indexes.

Table 3. Formulas to calculate metallurgical performance [24].

\begin{tabular}{|c|c|c|c|}
\hline Metallurgical Performance & Formula & & Nomenclature \\
\hline Recovery, \% & $R=\frac{C c}{A a}$ & $(1)$ & $\begin{array}{c}\mathrm{C} \text { and } \mathrm{A} \text { are the masses of concentrate and feed, respectively. } \\
\mathrm{c} \text { and a are the grades of the species of interest in the } \\
\text { concentrate and in the feed, respectively. }\end{array}$ \\
\hline Enrichment Ratio & $R e=\frac{c}{a}$ & $(2)$ & $\begin{array}{l}\mathrm{c} \text { and a are the grades of the species of interest in the } \\
\text { concentrate and in the feed, respectively. }\end{array}$ \\
\hline Selectivity & $I S=\sqrt{\frac{M * n}{m * N}}$ & (3) & $\begin{array}{l}\mathrm{M} \text { and } \mathrm{m} \text { are the grades of the species of interest in the } \\
\text { concentrate and in the tailings, respectively. } \\
\mathrm{N} \text { and } \mathrm{n} \text { are the grades of the gangue in the concentrate and in } \\
\text { the tailings, respectively. }\end{array}$ \\
\hline Concentration Ratio & $R_{c}=\frac{A}{C}$ & $(4)$ & $\mathrm{C}$ and $\mathrm{A}$ are the masses of concentrate and feed, respectively. \\
\hline Concentration Efficiency & $V=\frac{C}{A}=\frac{1}{R_{c}}$ & (5) & $\mathrm{C}$ and $\mathrm{A}$ are the masses of concentrate and feed, respectively. \\
\hline
\end{tabular}




\section{- Applied Assumptions}

To analyze the amount of chalcopyrite and pyrite present in the concentrates, the following mathematical relations were made based on the stoichiometric composition of chalcopyrite and pyrite, after having obtained the percentage of copper and iron in the concentrate by means of XRF.

This application is based on the assumption that all the copper present is associated with the chalcopyrite ore using a certain amount of iron. On the other hand, the remaining iron content is related to pyrite [18].

Equation (6) is used to estimate the percentage of chalcopyrite present in the concentrate.

$$
\% \text { Cpy }=\% C u\left(\frac{183.3}{63.5}\right)
$$

Equation (7) refers to the percentage of iron present as pyrite as estimated above.

$$
\% F e^{*}=\% F e-\% C u\left(\frac{55.8}{63.5}\right)
$$

Finally, Equation (8) represents the percentage of pyrite present in the concentrate.

$$
\% P y=\% F e^{*}\left(\frac{119.8}{55.8}\right)
$$

\section{Results and Discussion}

\subsection{Results of Collective Flotation Tests as a Function of PAX and RVO Concentration}

Figure $1 \mathrm{a}, \mathrm{b}$ shows the results obtained from the recovery and grade of copper and iron, as a function of PAX (Figure 1a) and RVO (Figure 1b) concentration. Figure 1a clearly shows that, in the absence of PAX, the lowest recovery and highest copper grade is obtained, which was to be expected due to the fact that under these conditions only the most hydrophobic particles of the ore, such as copper sulfides, should float. Subsequently, the addition of $20 \mathrm{~g} / \mathrm{t}$ of PAX collector produces an increase in recovery because this reagent gives hydrophobic characteristics to the ore particles, achieving at $40 \mathrm{~g} / \mathrm{t}$ the highest recovery and copper grade. Finally, at higher concentrations of this reagent, it can be seen that recovery and copper grade decrease considerably, suggesting an overdose of collecting reagent Accordingly, it should be noted that a $40 \mathrm{~g} / \mathrm{t}$ concentration of PAX collector allows for the best copper recoveries and grades in seawater, under the operating conditions set forth above. On the other hand, in relation to the recovery and iron grades obtained at different PAX concentrations, a similar trend can be observed in the curves obtained with copper, suggesting that the iron present in the concentrate is mainly associated to chalcopyrite and pyrite minerals.

Figure $1 \mathrm{~b}$ shows the results obtained for recovery and grade of copper and iron, as a function of the different studied RVO collector concentrations. In the figure, it can be seen that, in the case of copper, the recovery curve shows a significant increase when RVO is added to the process, regardless of its concentration, going from having a recovery of $58.8 \%$ in the absence of collector reagent to achieving an average recovery of close to $90 \%$ at the different RVO concentrations studied. Similarly, when analyzing the copper grade, it is observed that, at concentrations between 20 and $80 \mathrm{~g} / \mathrm{t}$ of RVO collector, the highest copper grades are achieved, which is close to $9 \%$, while, in the absence of collector and at a maximum concentration of $100 \mathrm{~g} / \mathrm{t}$, this grade decreases to values of $6.84 \%$ and $5.77 \%$, respectively. On the other hand, with respect to the recovery and grade of iron, it is possible to note that, at $80 \mathrm{~g} / \mathrm{t}$, the highest recovery and grade was achieved with $65.7 \%$ and $29.42 \%$, respectively. 


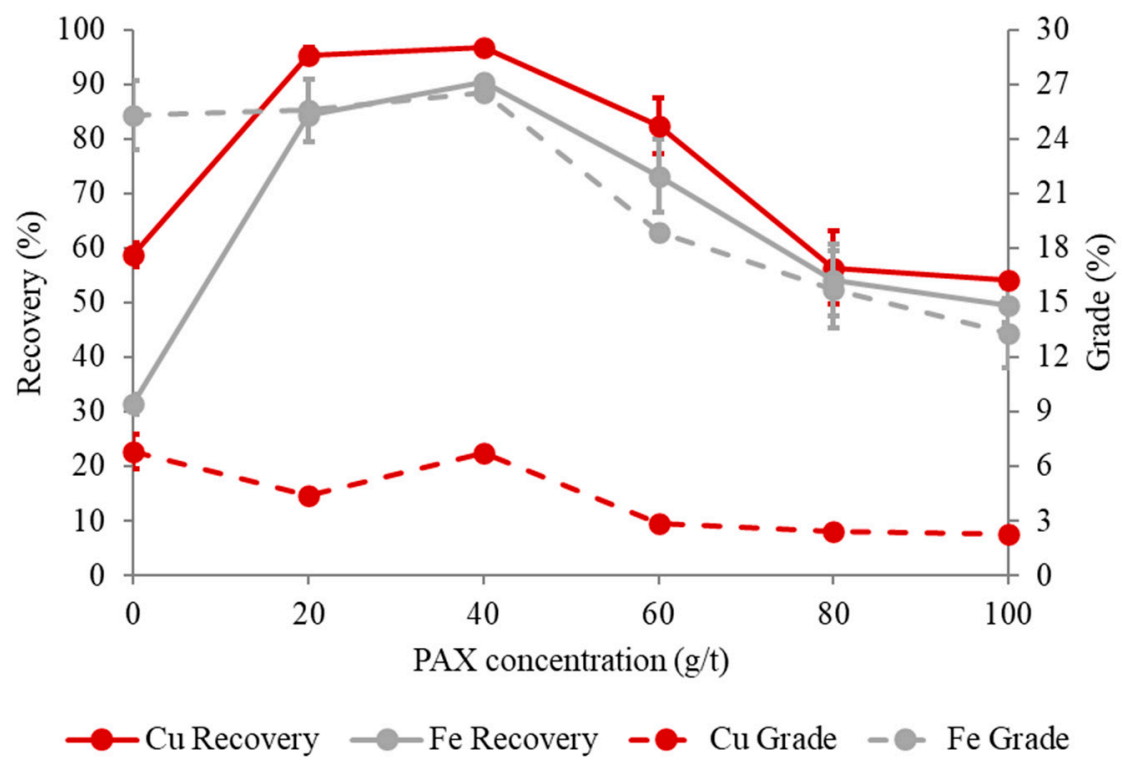

(a)

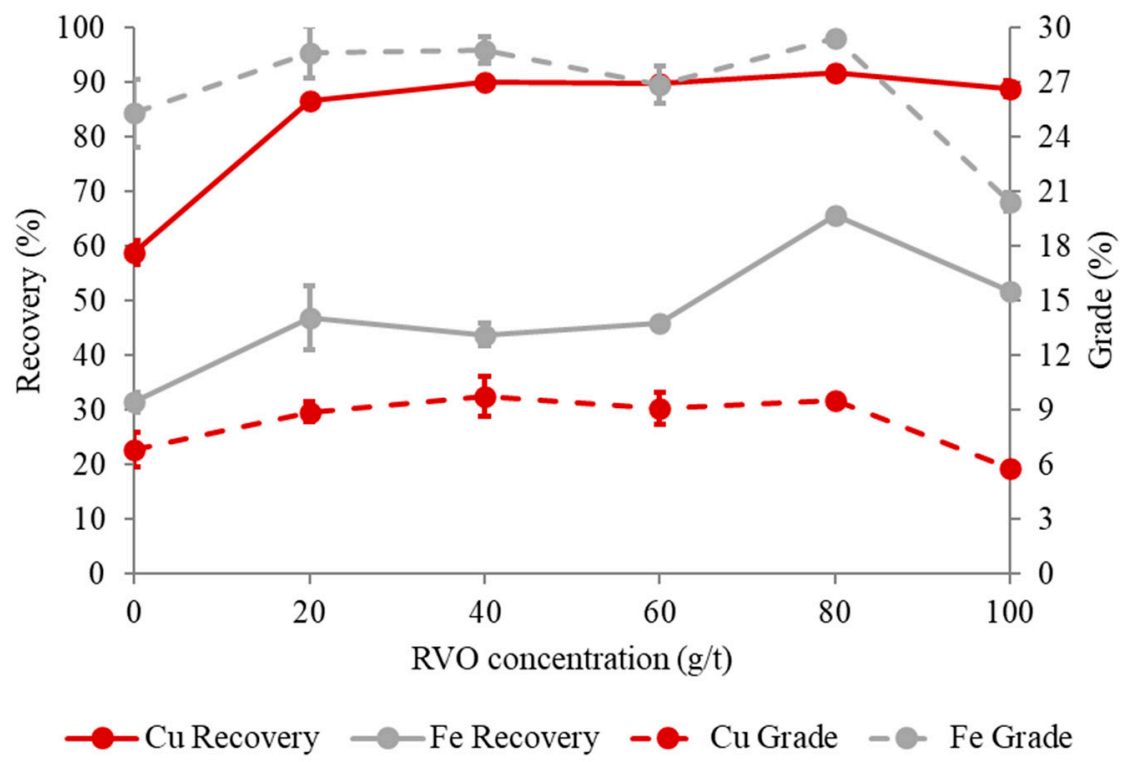

(b)

Figure 1. Recovery and grade of copper and iron obtained based on the PAX (a) and RVO (b) concentration, using $15 \mathrm{~g} / \mathrm{t}$ of MIBC and seawater.

It is important to point out that, within the interval between 20 and $80 \mathrm{~g} / \mathrm{t}$ of RVO, we have both the highest grades and the highest copper recoveries obtained with this collector, considerably improving the results obtained in its absence, which indicates that this reagent has a positive effect on the process and a great potential to be considered as a collector reagent in the flotation of copper sulfides with seawater.

Figure 2a,b shows the recovery and grade of both minerals (Cpy and Py) obtained as a function of the PAX and RVO concentration, respectively. In the figures, it can be seen that, for both minerals and collectors studied, there is a similar trend to the grades and recoveries obtained from each element, with the highest recoveries and grades of chalcopyrite at a concentration of $40 \mathrm{~g} / \mathrm{t}$. However, when comparing the results obtained in the presence of $40 \mathrm{~g} / \mathrm{t}$ of PAX and RVO separately (Figure 2a,b), it is noteworthy that 
the chalcopyrite grades in the presence of RVO (28.2\%) are significantly higher than those obtained with PAX (19.4\%). On the other hand, it is also shown that pyrite grades remain between $40 \%$ and $45 \%$ and the increase in the concentration of the RVO collector does not significantly affect the grade of this mineral. On the basis of the above, it can be stated that the same amount of pyrite is concentrated in the presence of RVO as with PAX, but there is a considerable increase in the percentage of chalcopyrite. The above indicates that RVO adsorbs preferentially on copper particles and that in seawater this reagent delivers favorable results in terms of both recovery and copper grades.

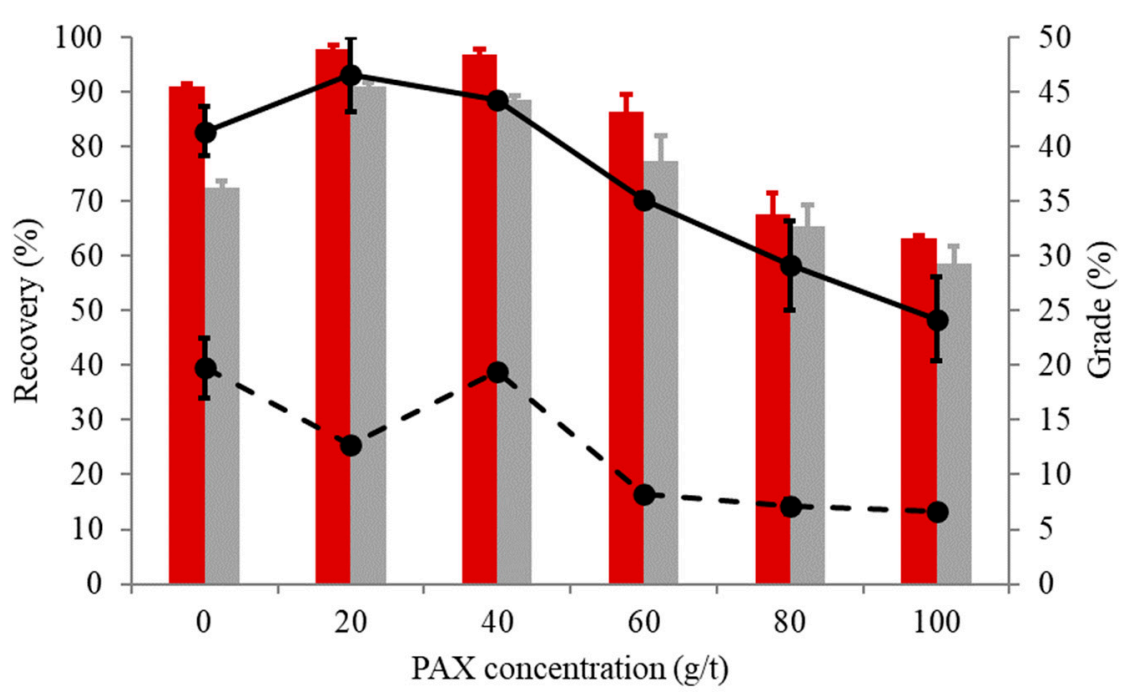

Cpy Recovery $\longrightarrow$ Py Recovery - - Cpy Grade —Py Grade

(a)

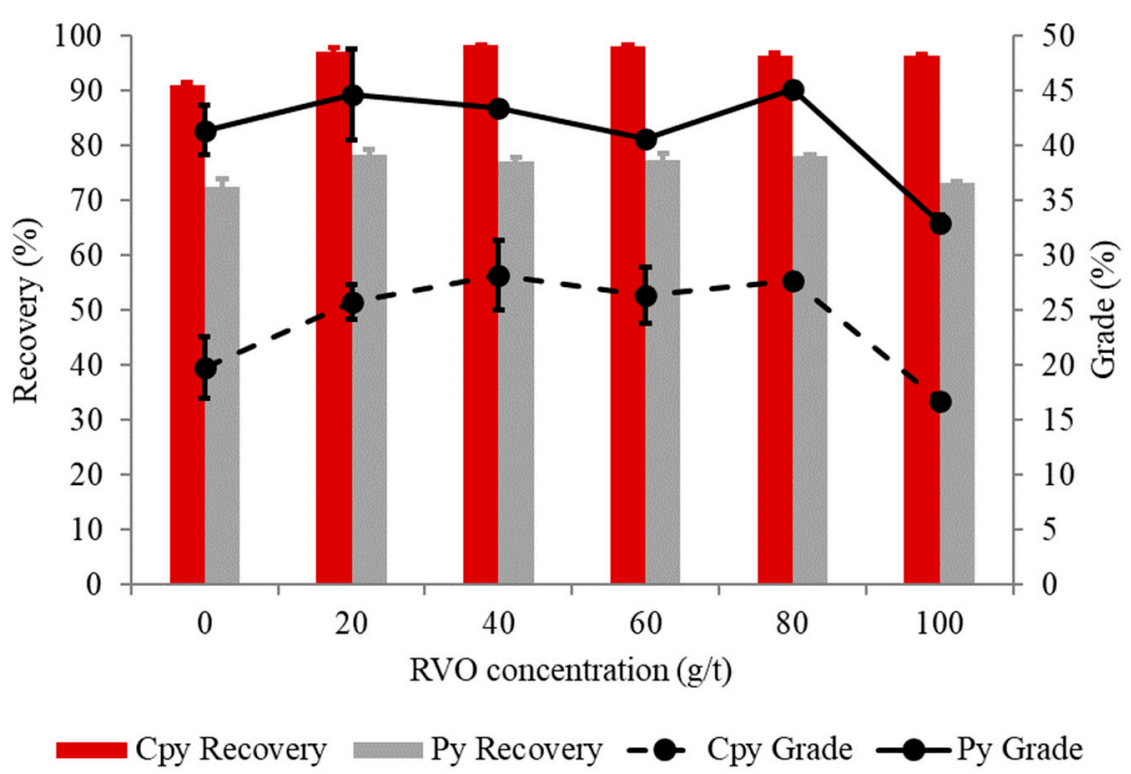

(b)

Figure 2. Recovery and grade of chalcopyrite and pyrite obtained based on the PAX (a) and RVO (b) concentration, using $15 \mathrm{~g} / \mathrm{t}$ of MIBC and seawater.

Tables 4 and 5 show the metallurgical indexes calculated for the PAX and RVO collectors in flotation tests. Within these indexes, we find the recovery; grade; enrichment ratio; selectivity index with respect to copper-silica and chalcopyrite-pyrite, because these 
species are the main gangue that are required to be removed during the flotation process; and the concentration ratio and yield.

Table 4. Metallurgical indexes obtained based on the PAX concentration, using $15 \mathrm{~g} / \mathrm{t}$ of MIBC and seawater.

\begin{tabular}{cccccccc}
\hline $\begin{array}{c}\text { PAX Dosage } \\
(\mathbf{g} / \mathbf{t})\end{array}$ & $\mathbf{R}(\mathbf{\%})$ & $\begin{array}{c}\text { Cu Grade } \\
\mathbf{( \% )}\end{array}$ & Re & $\begin{array}{c}\text { IS } \\
(\mathbf{C u}-\mathbf{S i})\end{array}$ & $\begin{array}{c}\text { IS } \\
\text { (Cpy-Py) }\end{array}$ & Rc & V \\
\hline 0 & 58.78 & 6.84 & 4.69 & 6.27 & 1.95 & 8.02 & 0.12 \\
20 & 95.41 & 4.41 & 2.99 & 14.92 & 2.06 & 3.15 & 0.32 \\
40 & 96.85 & 6.70 & 1.93 & 7.62 & 1.98 & 1.99 & 0.50 \\
60 & 82.32 & 2.85 & 1.93 & 3.42 & 1.36 & 2.36 & 0.42 \\
80 & 56.40 & 2.45 & 1.47 & 1.65 & 1.05 & 2.63 & 0.38 \\
100 & 54.05 & 2.29 & 1.34 & 1.47 & 1.10 & 2.48 & 0.40 \\
\hline
\end{tabular}

Table 5. Metallurgical indexes obtained based on the RVO concentration, using $15 \mathrm{~g} / \mathrm{t}$ of MIBC and seawater.

\begin{tabular}{cccccccc}
\hline $\begin{array}{c}\text { RVO } \\
\text { Dosage (g/t) }\end{array}$ & R (\%) & $\begin{array}{c}\text { Cu Grade } \\
(\mathbf{\%})\end{array}$ & Re & $\begin{array}{c}\text { IS } \\
\text { (Cu-Si) }\end{array}$ & $\begin{array}{c}\text { IS } \\
\text { (Cpy-Py) }\end{array}$ & Rc & V \\
\hline 0 & 58.78 & 6.84 & 4.69 & 6.27 & 1.95 & 8.02 & 0.12 \\
20 & 86.50 & 8.91 & 5.62 & 11.14 & 3.09 & 6.53 & 0.16 \\
40 & 90.06 & 9.74 & 6.29 & 12.89 & 4.03 & 7.01 & 0.14 \\
60 & 89.75 & 9.10 & 5.87 & 11.05 & 3.78 & 6.56 & 0.15 \\
80 & 91.74 & 9.55 & 3.17 & 8.19 & 2.78 & 3.46 & 0.29 \\
100 & 88.80 & 5.77 & 3.77 & 6.59 & 3.08 & 4.26 & 0.24 \\
\hline
\end{tabular}

From the results presented in Table 4 , it can be seen that the best metallurgical indexes with respect to copper were achieved at 20 and $40 \mathrm{~g} / \mathrm{t}$ of PAX collector, being $20 \mathrm{~g} / \mathrm{t}$ the case in which the highest enrichment ratio, concentration ratio and selectivity of copper with respect to the main gangue, silica and pyrite and $40 \mathrm{~g} / \mathrm{t}$ the case in which the highest recovery and grade of copper is achieved. With regard to the capacity indexes obtained at these conditions, it is noted that the highest concentration ratio occurs at $20 \mathrm{~g} / \mathrm{t}$ and, consequently, the highest concentration yield at $40 \mathrm{~g} / \mathrm{t}$. On the other hand, in relation to the RVO collector from the results presented in Table 5 , it can be seen that the best metallurgical indexes with respect to copper were achieved at 40 and $80 \mathrm{~g} / \mathrm{t}$ of RVO collector, being $40 \mathrm{~g} / \mathrm{t}$ the case in which the highest grade, enrichment ratio, concentration ratio and selectivity of copper with respect to the main gangue, silica and pyrite and $80 \mathrm{~g} / \mathrm{t}$ the case in which the highest copper recovery is achieved.

Comparing the results obtained in the presence of PAX and RVO, it is possible to establish that, at $40 \mathrm{~g} / \mathrm{t}$ of RVO collector, the flotation process achieves better metallurgical indexes than those obtained with PAX, in which it can be clearly indicated that the copper grade, the enrichment ratio, the selectivity indexes and the concentration ratio are better when using RVO than PAX, being the copper recovery the only index favored in the presence of PAX.

\subsection{Results of Collective Flotation Tests Using Mixtures of RVO/PAX Collectors in Different Proportions}

Tests were performed by mixing both collector reagents with the aim of studying possible configurations of the collectors that would have favorable effects on metallurgical indexes.

Figure 3 shows, in the same way as the previous cases, the recovery curves and copper and iron grades obtained as a function of the different RVO/PAX mixtures studied. In the figure, it can be seen that, in the case of copper, the recovery obtained for the $80 / 20,60 / 40$, $40 / 60$ and $20 / 80$ reagent mixtures is approximately constant, reaching a recovery close to $98 \%$. Meanwhile, in cases where separate reagents were used, it can be seen that the 
recovery of copper is lower with $100 \mathrm{~g} / \mathrm{t}$ of PAX than when using the same concentration of RVO, with $88.80 \%$ and $54.05 \%$, respectively. By analyzing the copper grade, it can be seen that the highest grades are obtained in the 80/20 and 60/40 RVO/PAX blends, which corresponded to $5.51 \%$ and $7.40 \%$.

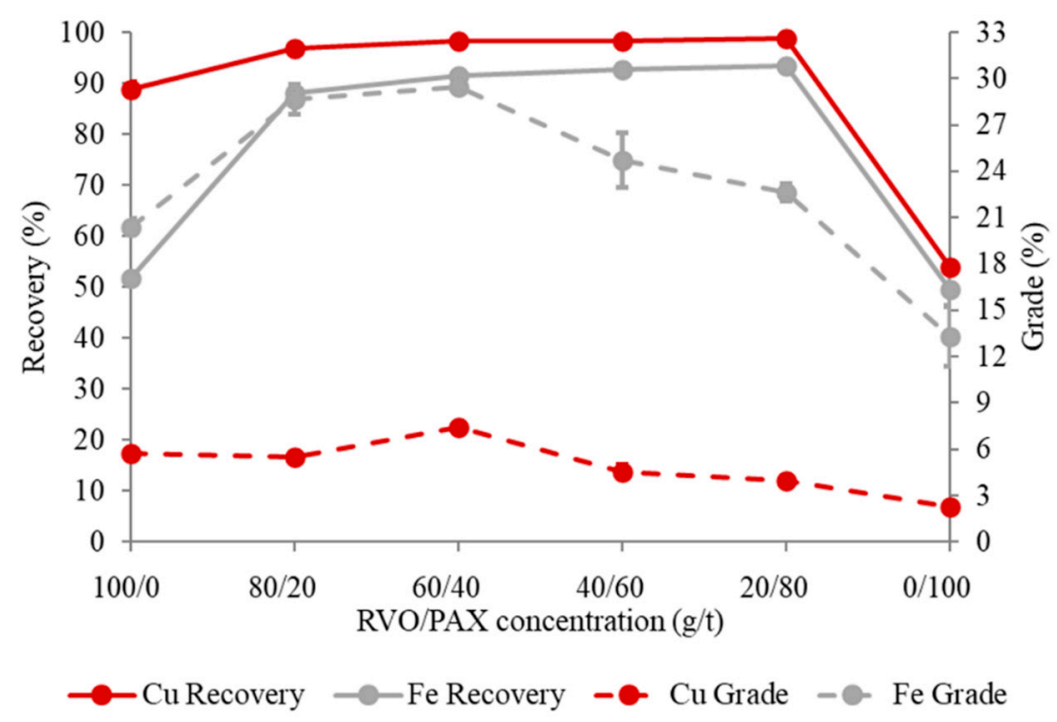

Figure 3. Recovery and grade of copper and iron obtained based on the RVO/PAX concentration, using $15 \mathrm{~g} / \mathrm{t}$ of MIBC and seawater.

On the other hand, with respect to the recovery and iron grades obtained as a function of the RVO/PAX mixtures, it can be seen that the curves show a behavior similar to that of copper, reaching a recovery for the $80 / 20,60 / 40,40 / 60$ and 20/80 cases of approximately $90 \%$, and, with respect to the iron grade, it can be seen that the highest grades of this element are obtained in the $80 / 20$ and $60 / 40 \mathrm{RVO} / \mathrm{PAX}$ mixtures, which were close to $30 \%$.

When comparing the results of the recoveries and grades obtained in the mixtures with those obtained only with RVO (Figure 1b), it can be seen that, in the mixture, the presence of PAX favors the recovery of copper obtained with RVO but affects the copper grade obtained in the concentrate.

With respect to the mineralogy associated with the process, Figure 4 shows the recovery and grade of chalcopyrite and pyrite obtained for each mixture according to the assumptions indicated above. In the figure, it can be seen that the highest recovery and chalcopyrite grade was obtained with an RVO/PAX mix of $60 / 40$, obtaining $98.6 \%$ and $21.4 \%$, respectively.

Comparing the results obtained with the mixtures against those obtained only with RVO (Figures 2 and 4), it can be observed that the presence of PAX generates a slight increase in the recovery of chalcopyrite but a decrease in the grade of this mineral and, in the same way, significantly increases the presence of pyrite in the concentrates, being the mixture RVO/PAX 60/40 the one that presents the best results.

Table 6 presents the metallurgical indexes calculated for the flotation test set performed. It shows that, in general, the best metallurgical indexes with respect to copper were achieved with the RVO/PAX 60/40 mixture, especially in terms of process selectivity. 


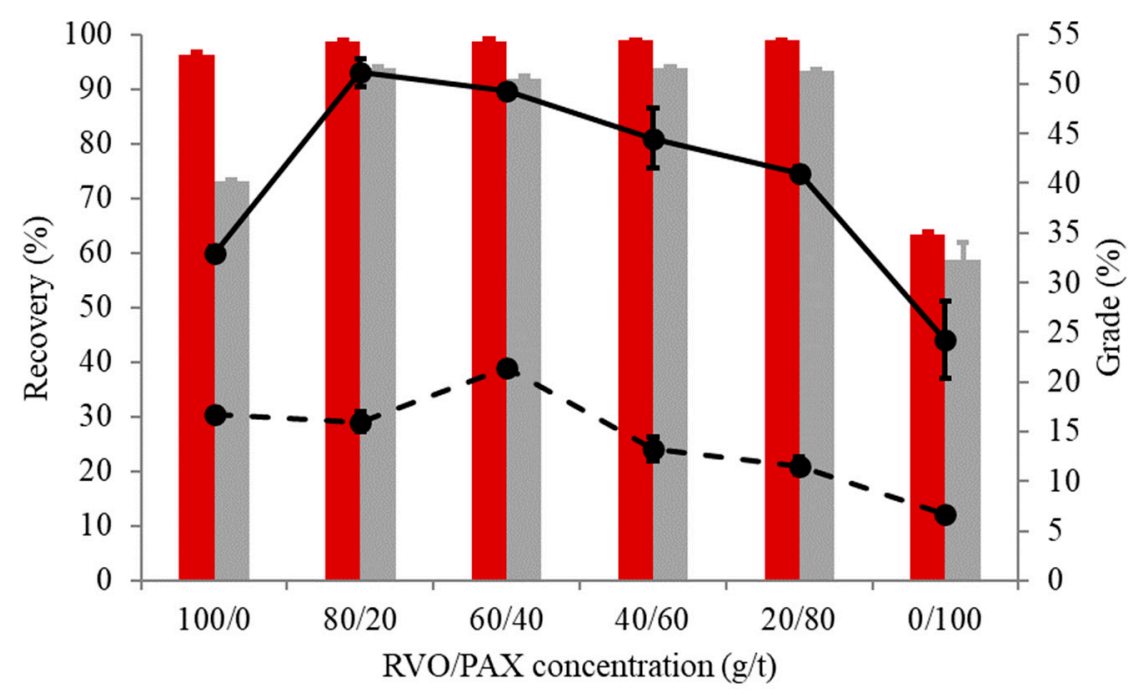

Cpy Recovery $\backsim$ Py Recovery - - Cpy Grade —-Py Grade

Figure 4. Recovery and grade of chalcopyrite and pyrite obtained based on the RVO/PAX concentration, using $15 \mathrm{~g} / \mathrm{t}$ of MIBC and seawater.

Table 6. Metallurgical indexes obtained based on the RVO/PAX concentration, using $15 \mathrm{~g} / \mathrm{t}$ of MIBC and seawater.

\begin{tabular}{cccccccc}
\hline $\begin{array}{c}\text { RVO/PAX } \\
\text { Dosage (g/t) }\end{array}$ & R (\%) & $\begin{array}{c}\text { Cu Grade } \\
\text { (\%) }\end{array}$ & Re & $\begin{array}{c}\text { IS } \\
\text { (Cu-Si) }\end{array}$ & $\begin{array}{c}\text { IS } \\
\text { (Cpy-Py) }\end{array}$ & Rc & V \\
\hline $100 / 0$ & 88.80 & 5.77 & 3.77 & 6.59 & 3.08 & 4.26 & 0.24 \\
$80 / 20$ & 96.94 & 5.51 & 3.22 & 13.80 & 2.24 & 3.33 & 0.30 \\
$60 / 40$ & 98.24 & 7.40 & 2.25 & 13.78 & 2.53 & 2.29 & 0.44 \\
$40 / 60$ & 98.41 & 4.56 & 2.36 & 13.38 & 2.37 & 2.41 & 0.42 \\
$20 / 80$ & 98.75 & 4.00 & 2.11 & 12.91 & 2.53 & 2.14 & 0.47 \\
$0 / 100$ & 54.05 & 2.29 & 1.34 & 1.47 & 1.10 & 2.48 & 0.40 \\
\hline
\end{tabular}

When comparing the results under this condition (Table 6) with the best results obtained with the separate action of each collector (Tables 4 and 5), it can be established that the use of reagent mixtures improves the copper recovery compared to that obtained with both collectors separately, while the grade and the enrichment ratio were improved when compared with PAX alone. On the other hand, compared to the selectivity indexes with respect to the main gangue, it can be seen that the selectivity of copper, with respect to silica, increased when using mixtures, while, with respect to pyrite, it was only increased when comparing it with PAX. Finally, in. relation to the concentration ratio, the use of mixtures increased this index with respect to the value obtained with PAX, but, when compared with those obtained with RVO alone, these values are significantly higher, generating the concentrates with the lowest amount of mass in the presence of RVO.

In general, the reagent mixtures generated a positive effect, achieving $98.24 \%$ and $7.40 \%$ maximum copper recovery and grade, respectively, when using an RVO/PAX 60/40 mixture. Although it is true that the grade is higher than that obtained with PAX and lower compared with the cases of RVO, the results obtained with this mixture with respect to the other metallurgical indexes are attractive considering that the studied process corresponds to a stage of collective flotation. 


\subsection{Seawater Flotation Results as a Function of MIBC Concentration}

3.3.1. Results of Collective Flotation Tests as a Function of MIBC Concentration in Presence of $40 \mathrm{~g} / \mathrm{t}$ PAX and RVO, Separately

Figure 5 presents the results of copper and iron recovery and grade obtained as a function of MIBC concentration. In the figure, it is possible to observe that the recovery curves for both elements showed a similar trend and a constant behavior when varying the MIBC concentration, while, in the case of copper and iron grades, they increase as the concentration of the foaming agent increases. A minimum recovery of copper in the absence of foaming agent is obtained, corresponding to $96.6 \%$ and a maximum of $97.8 \%$ at $20 \mathrm{~g} / \mathrm{t}$ MIBC. On the other hand, in relation to the recovery of iron, a behavior similar to that of copper is obtained, with a minimum recovery of $89.7 \%$ in the absence of foaming agent and a maximum recovery of $90.8 \%$ using $10 \mathrm{~g} / \mathrm{t}$ of MIBC. With respect to the grades, in the case of copper, the lowest value was $5.43 \%$ and occurs at $5 \mathrm{~g} / \mathrm{t} \mathrm{MIBC}$, from which it begins to increase progressively and slightly depending on the concentration of foaming agent, reaching the maximum value of $7.23 \%$ at $20 \mathrm{~g} / \mathrm{t}$. On the other hand, when analyzing the iron grade obtained in the concentrate, it is emphasized that there is a similar behavior to the previous one, where the lowest grade obtained for iron was $23 \%$ at $5 \mathrm{~g} / \mathrm{t} \mathrm{MIBC}$, while the highest was $28.7 \%$ at $20 \mathrm{~g} / \mathrm{t}$ foaming agent. In this way, and according to the previous evidence, it can be established that for this test with $40 \mathrm{~g} / \mathrm{t}$ of PAX collector, the best results in terms of grade and copper recovery are obtained with $20 \mathrm{~g} / \mathrm{t}$ of MIBC foaming agent.

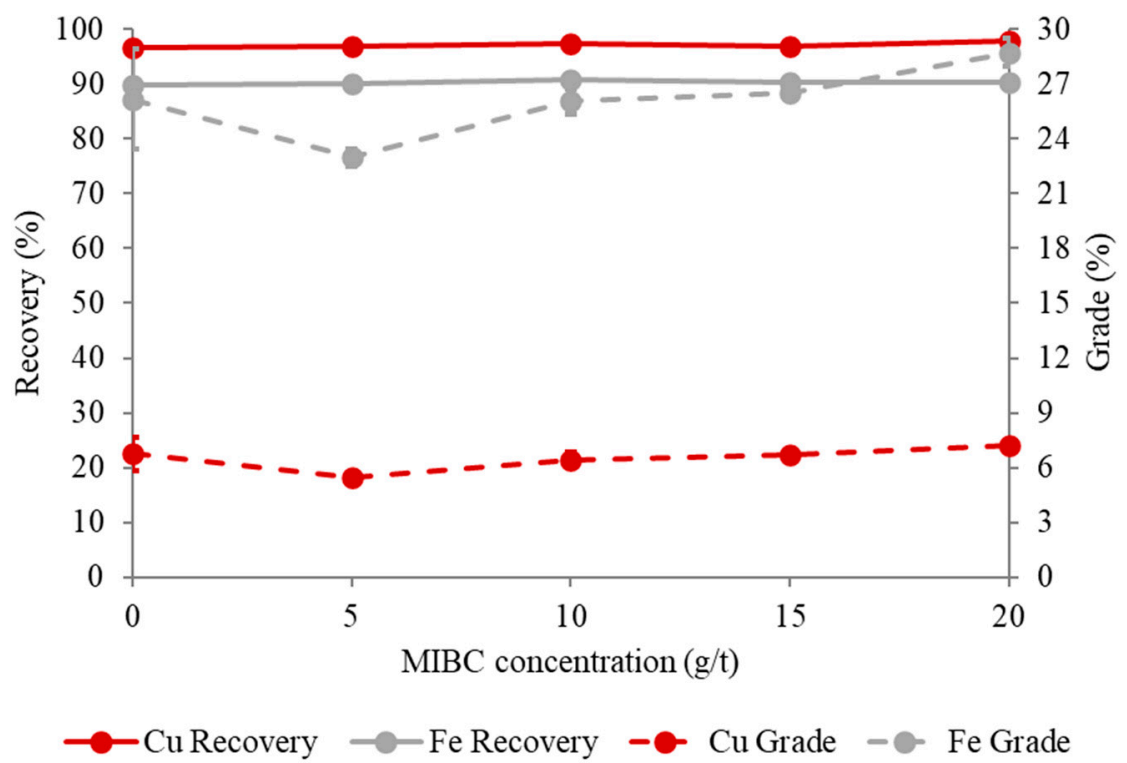

Figure 5. Recovery and grade of copper and iron obtained based on the MIBC concentration, using $40 \mathrm{~g} / \mathrm{t}$ PAX and seawater.

Figure 6 shows the recovery and grade curves of copper and iron obtained at the different concentrations of foaming agent for a $40 \mathrm{~g} / \mathrm{t}$ RVO concentration. In the figure, it is possible to emphasize that the recovery of copper has a stable behavior that oscillates between $87 \%$ and $90 \%$ in the interval that goes from 0 to $15 \mathrm{~g} / \mathrm{t}$, presenting the minor recovery at $20 \mathrm{~g} / \mathrm{t}$, which was of $84.7 \%$. On the other hand, in relation to the recovery of iron, it can be seen that the curve obtained showed a behavior similar to that of copper, i.e., recovery remains stable at around 56\%, while at $15 \mathrm{~g} / \mathrm{t}$, unlike the case of copper which slightly increased its recovery, for iron it decreases markedly to around $44 \%$ approximately. In relation to the grades obtained as a function of the MIBC concentration, in the case of copper, it can be observed that in the absence of foaming agent a grade of $9.74 \%$ is achieved, which then, by adding low concentrations of foaming agents, corresponding to 5 and $10 \mathrm{~g} / \mathrm{t}$, decreases to values of $8.33 \%$ and $7.92 \%$, respectively. However, at higher concentrations, corresponding to 15 and $20 \mathrm{~g} / \mathrm{t}$, a considerable increase is achieved, reaching values of $9.74 \%$ and $9.51 \%$, respectively. With 
respect to the iron grade, a similar behavior can be seen to that obtained in the case of copper, which at $0 \mathrm{~g} / \mathrm{t}$ has a value of 28.37\%; at concentrations of 5 and $10 \mathrm{~g} / \mathrm{t}$ decreases to $27.79 \%$ and $27.26 \%$, respectively; and at higher concentrations the grade is reversed, obtaining the highest value at $15 \mathrm{~g} / \mathrm{t}$ of MIBC, corresponding to $28.79 \%$.

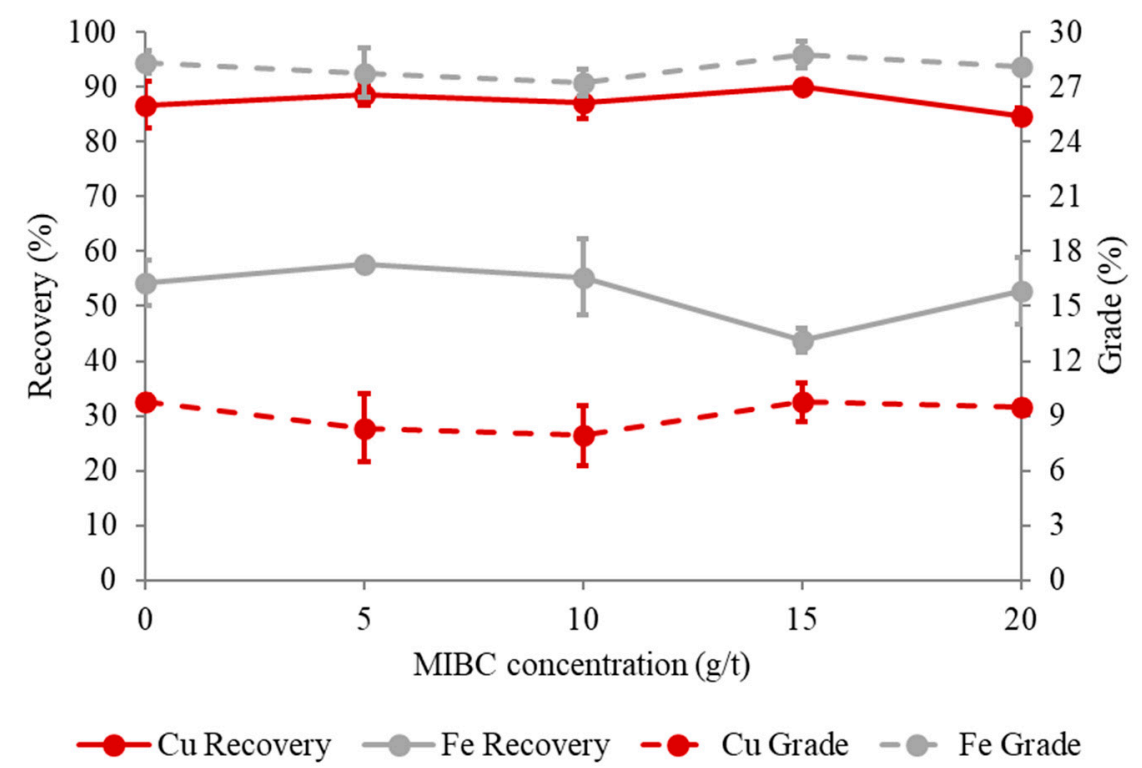

Figure 6. Recovery and grade of copper and iron obtained based on the MIBC concentration, using $40 \mathrm{~g} / \mathrm{t}$ RVO and seawater.

On the other hand, Figure 7a,b shows the percentages of chalcopyrite and pyrite obtained as a function of the concentration of foaming agent. It shows a similar behavior to that obtained with copper and iron grades, where, as the concentration of foaming agent increases, the grades of both minerals increase, the highest grades being obtained at a dose of $20 \mathrm{~g} / \mathrm{t}$ MIBC, $20.9 \%$ for chalcopyrite. With regard to the recovery of these minerals, this index shows little variation depending on the concentration of the foaming agent, reaching a maximum value of $98.3 \%$ at $20 \mathrm{~g} / \mathrm{t}$ of MIBC, thus improving the results obtained before $15 \mathrm{~g} / \mathrm{t}$.

In addition, Figure $7 \mathrm{~b}$ shows the recovery and grade of chalcopyrite and pyrite obtained in the presence of RVO. It can be seen that chalcopyrite is directly related to copper grade, so at 0 and $15 \mathrm{~g} / \mathrm{t}$ it has its highest grade with a value of $28.2 \%$. On the other hand, it is observed that the pyrite grade in the concentrate remains practically constant between $42 \%$ and $43 \%$. With regard to the recoveries of both minerals, it is observed that they remain practically constant throughout the range of foaming agent concentrations studied, obtaining the highest recovery of chalcopyrite at $15 \mathrm{~g} / \mathrm{t}$ MIBC with a value of $98.2 \%$, while the lowest recovery of pyrite is reached at $20 \mathrm{~g} / \mathrm{t}$.

Table 7 presents the metallurgical indexes obtained as a function of the concentration of foaming agent. It shows that, at $20 \mathrm{~g} / \mathrm{t}$ MIBC, the best metallurgical indexes are indeed obtained. It should be pointed out that the Cu-Si selectivity index increases considerably in the presence of this dose of MIBC, reaching 11.99, as well as for the Cpy-Py case, where a value of 2.43 is obtained. Finally, with respect to the capacity indexes, the concentration ratio is higher in comparison to the other MIBC concentrations, indicating that the concentrate obtained in the process has a lower mass quantity, making the process more efficient in both collective and selective terms. Consequently, the lowest concentration yield is obtained of all the conditions studied, confirming the fact of having a lower mass quantity in the concentrate with respect to the process feed. On the other hand, in relation to the RVO collector from the results presented in Table 8 , it is observed that the best indexes are obtained at a concentration of $15 \mathrm{~g} / \mathrm{t}$, highlighting both the enrichment ratio of 6.29 , the selectivity index Cu-Si of 12.89 and Cpy-Py of 4.03, as well as the concentration ratio of 
7.01, indicating a high selective capacity in the process in this condition of operation and dosage of reagents in the presence of seawater.

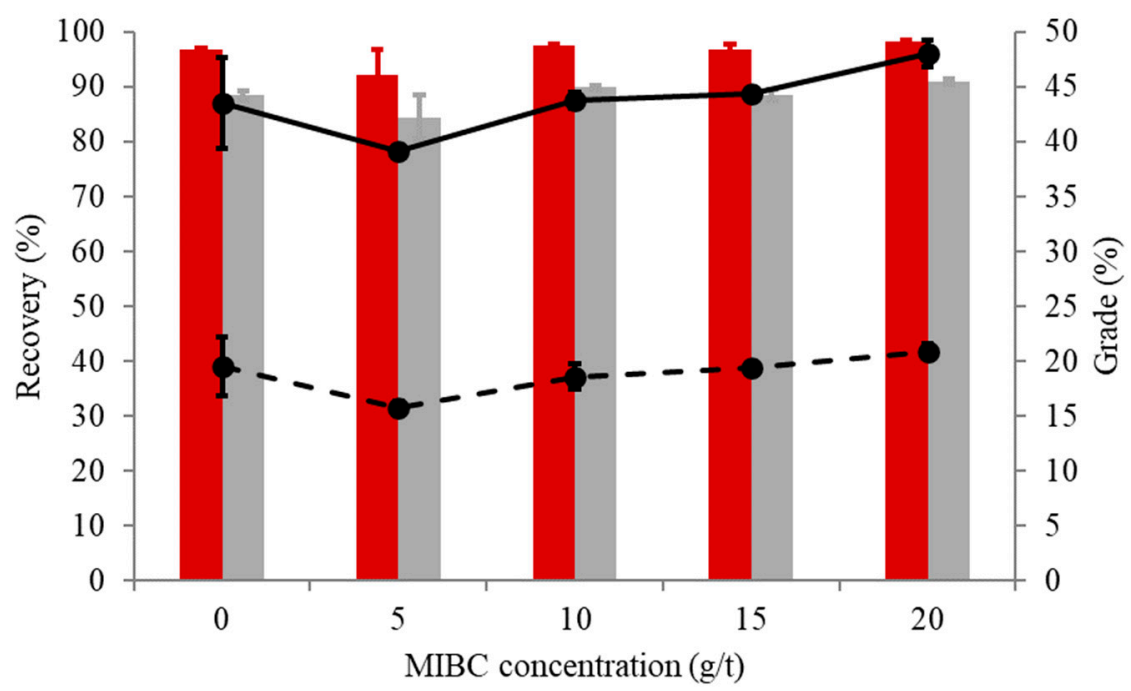

Cpy Recovery $\longrightarrow$ Py Recovery - Cpy Grade $\longrightarrow$ Py Grade

(a)

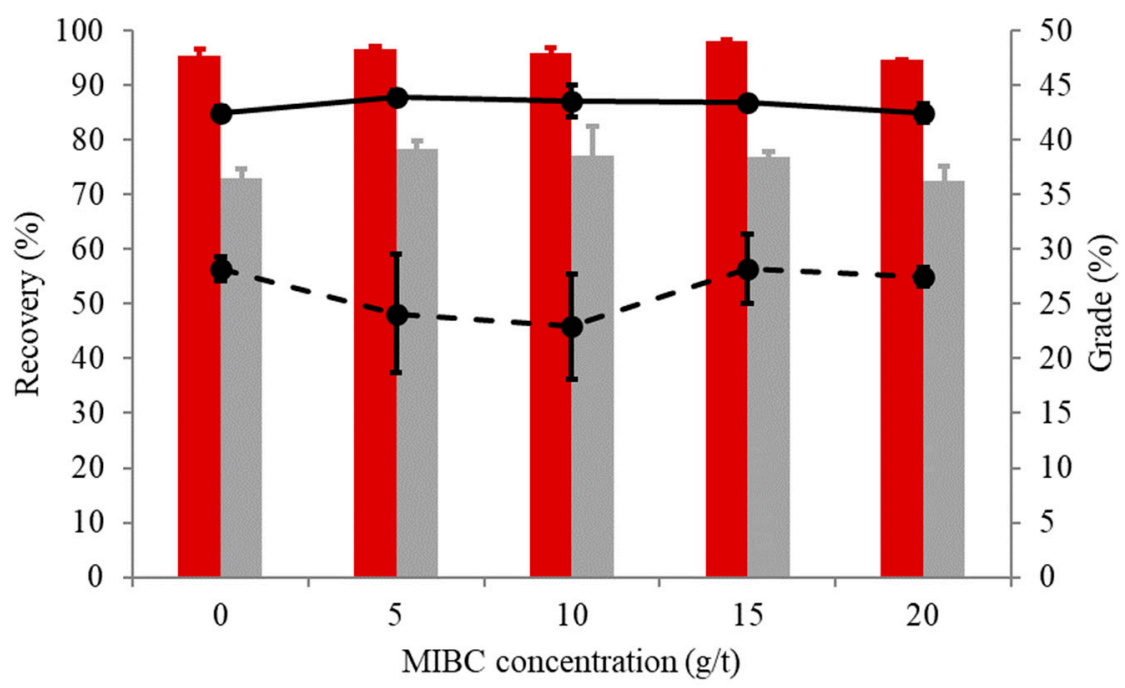

Cpy Recovery $\longrightarrow$ Py Recovery - C Cpy Grade - Py Grade

(b)

Figure 7. Recovery and grade of chalcopyrite and pyrite obtained based on the MIBC concentration, using $40 \mathrm{~g} / \mathrm{t}$ PAX (a) and RVO (b), separately, and seawater. 
Table 7. Metallurgical indexes obtained based on the MIBC concentration, using $40 \mathrm{~g} / \mathrm{t}$ PAX and seawater.

\begin{tabular}{cccccccc}
\hline $\begin{array}{c}\text { MIBC } \\
\text { Dosage (g/t) }\end{array}$ & R (\%) & $\begin{array}{c}\text { Cu Grade } \\
\mathbf{( \% )}\end{array}$ & Re & $\begin{array}{c}\text { IS } \\
\text { (Cu-Si) }\end{array}$ & $\begin{array}{c}\text { IS } \\
\text { (Cpy-Py) }\end{array}$ & Rc & V \\
\hline 0 & 96.62 & 6.74 & 1.99 & 7.77 & 1.99 & 2.06 & 0.49 \\
5 & 90.98 & 5.42 & 1.92 & 5.50 & 1.48 & 2.13 & 0.47 \\
10 & 97.44 & 6.42 & 2.04 & 9.24 & 2.16 & 2.10 & 0.48 \\
15 & 96.85 & 6.70 & 1.93 & 7.62 & 1.98 & 1.99 & 0.50 \\
20 & 97.84 & 7.23 & 2.27 & 11.99 & 2.43 & 2.33 & 0.43 \\
\hline
\end{tabular}

Table 8. Metallurgical indexes obtained based on the MIBC concentration, using $40 \mathrm{~g} / \mathrm{t}$ RVO and seawater.

\begin{tabular}{cccccccc}
\hline $\begin{array}{c}\text { MIBC } \\
\text { Dosage (g/t) }\end{array}$ & R (\%) & $\begin{array}{c}\text { Cu Grade } \\
\mathbf{( \% )}\end{array}$ & Re & $\begin{array}{c}\text { IS } \\
\text { (Cu-Si) }\end{array}$ & $\begin{array}{c}\text { IS } \\
\text { (Cpy-Py) }\end{array}$ & Rc & V \\
\hline 0 & 86.76 & 9.74 & 3.56 & 8.06 & 2.76 & 8.02 & 0.12 \\
5 & 88.61 & 8.33 & 3.95 & 8.59 & 2.78 & 4.48 & 0.22 \\
10 & 87.10 & 7.92 & 4.00 & 8.10 & 2.63 & 4.61 & 0.22 \\
15 & 90.06 & 9.74 & 6.29 & 12.89 & 4.03 & 7.01 & 0.14 \\
20 & 84.70 & 9.51 & 3.56 & 7.11 & 2.58 & 4.23 & 0.24 \\
\hline
\end{tabular}

In the same context, the selectivity index of chalcopyrite on pyrite obtained at $15 \mathrm{~g} / \mathrm{t}$ MIBC stands out due to its high value, which was 4 . According to the literature, this represents a good metallurgical result for the flotation process, which, integrated with the rest of the indexes studied, makes this case a good operating condition in terms of feasibility for its use in industrial processes. Finally, the concentration yield is highlighted, which indicates that, of the total mass fed to the flotation, only $14 \%$ is transferred to the concentrate stream, suggesting high selectivity for the process.

3.3.2. Results of Collective Flotation Tests as a Function of MIBC Concentration in Presence of RVO/PAX 60/40 Mixture

Figure 8 presents the results of copper and iron recovery and grade obtained as a function of MIBC concentration using a $60 / 40 \mathrm{~g} / \mathrm{t}$ RVO/PAX mixture as collector. In general, it is possible to observe that all the curves obtained have a practically stable behavior as a function of the MIBC concentration. With regard to copper recovery, it can be seen that its behavior is homogeneous throughout the whole range of frother agent concentration, i.e., it remains constant with a value close to $98 \%$. On the other hand, the recovery of iron also behaves in a stable way, maintaining a recovery that ranges between $90.78 \%$ and $92.4 \%$.

With respect to the grades obtained, it can be observed that, with respect to the copper grade, it remains stable with a value close to $7 \%$, reaching its maximum value in the absence of MIBC corresponding to $7.58 \%$ of copper in the concentrate and a minimum value at $5 \mathrm{~g} / \mathrm{t}$ corresponding to $7.05 \%$. On the other hand, analysis of the iron grade may indicate that it exhibits constant behavior as a function of the MIBC concentration, the maximum and minimum iron grade being obtained at 15 and $5 \mathrm{~g} / \mathrm{t}$, respectively, with values of $29.49 \%$ and $28.80 \%$ for each of the aforementioned doses. 


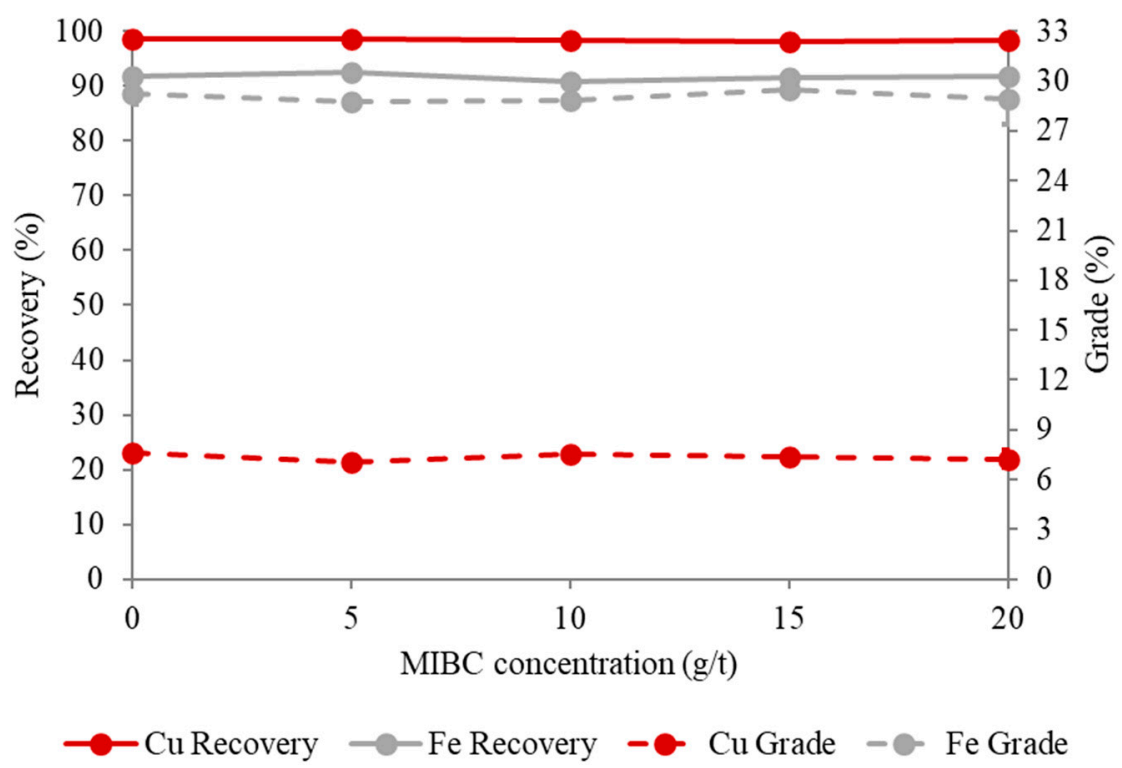

Figure 8. Recovery and grade of copper and iron obtained based on the MIBC concentration, using RVO/PAX 60/40 and seawater.

Figure 9 shows the grade and recovery of chalcopyrite and pyrite obtained at the different concentrations of foaming agent studied. It is possible to observe in the figure that the highest chalcopyrite content, as well as the highest copper grade, is achieved in the absence of foaming agent and corresponds to $21.9 \%$ together with $48.5 \%$ pyrite. Meanwhile, the lowest grade of the latter ore was $47.7 \%$ and is reached at a concentration of $10 \mathrm{~g} / \mathrm{t}$ MIBC, which coincides with one of the lowest values for iron grade. With regard to the recovery of these minerals, in general, it is maintained without great alterations depending on the concentration of the foaming agent; however, the maximum recoveries of chalcopyrite are reached at 0 and $5 \mathrm{~g} / \mathrm{t}$ with values of approximately $98.9 \%$, while the maximum recovery of pyrite occurs at $5 \mathrm{~g} / \mathrm{t}$ with a value of $92.5 \%$.

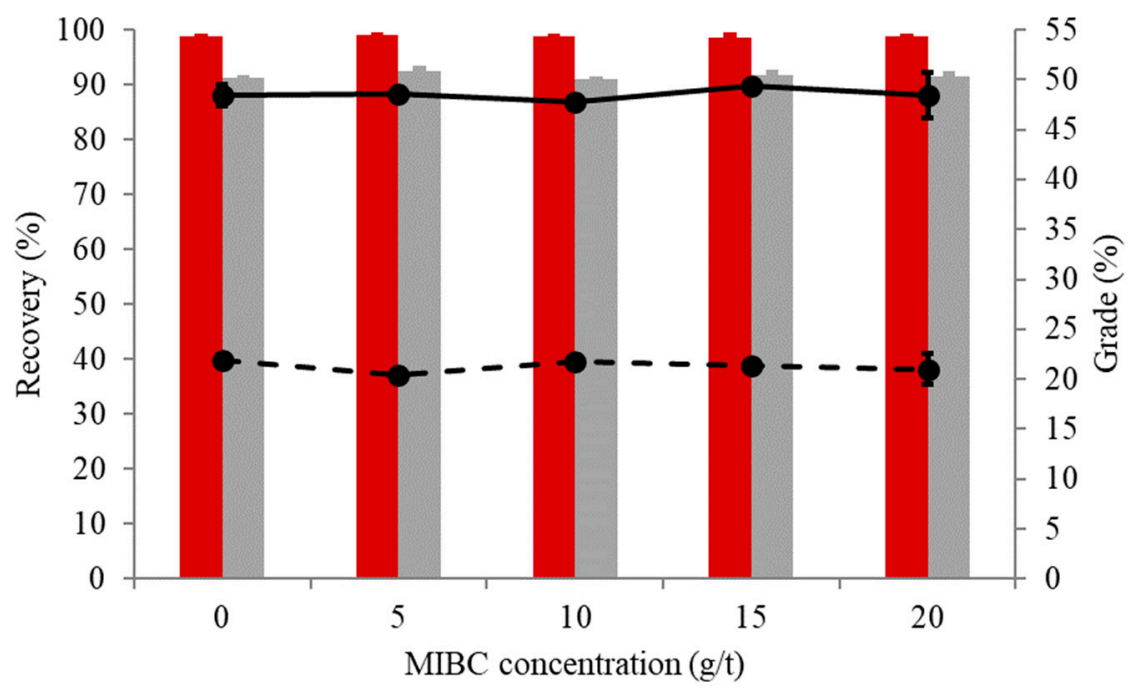

Cpy Recovery $\longrightarrow$ Py Recovery - C Cpy Grade $\rightarrow$ Py Grade

Figure 9. Recovery and grade of chalcopyrite and pyrite obtained based on the MIBC concentration, using RVO/PAX 60/40 and seawater. 
Table 9 presents the metallurgical indexes obtained according to the different concentrations of foaming agent. It shows that, with respect to copper recovery and grade, there is a very slight variation between each test depending on the concentration of the foaming agent and the highest result is obtained in the absence of MIBC. Compared to the enrichment ratio, a similar behavior is observed, with the highest enrichment at $15 \mathrm{~g} / \mathrm{t}$ MIBC. On the other hand, compared to the selectivity indexes, the Cu-Si selectivity index presented its highest values at $5 \mathrm{~g} / \mathrm{t}$ of frother, while for the Cpy-Py case the highest value was obtained in the absence of MIBC. Finally, in relation to the capacity indexes, it is observed that the highest concentration ratio was achieved in the absence of foaming agent along with the best performance.

Table 9. Metallurgical indexes obtained based on the MIBC concentration, using RVO/PAX 60/40 and seawater.

\begin{tabular}{cccccccc}
\hline $\begin{array}{c}\text { MIBC } \\
\text { Dosage (g/t) }\end{array}$ & R (\%) & $\begin{array}{c}\text { Cu Grade } \\
(\mathbf{\%})\end{array}$ & Re & $\begin{array}{c}\text { IS } \\
\text { (Cu-Si) }\end{array}$ & $\begin{array}{c}\text { IS } \\
\text { (Cpy-Py) }\end{array}$ & Rc & V \\
\hline 0 & 98.66 & 7.58 & 2.14 & 14.65 & 2.88 & 4.26 & 0.24 \\
5 & 98.67 & 7.05 & 2.22 & 15.06 & 2.74 & 2.26 & 0.44 \\
10 & 98.40 & 7.50 & 2.23 & 13.75 & 2.79 & 2.27 & 0.44 \\
15 & 98.24 & 7.40 & 2.25 & 13.78 & 2.53 & 2.29 & 0.44 \\
20 & 98.43 & 7.25 & 2.16 & 12.85 & 2.64 & 2.20 & 0.45 \\
\hline
\end{tabular}

From the results obtained for the different concentrations of MIBC for the best separate collectors (Tables 7 and 8) and the mixture of these (Table 9), it can be seen that, except for recovery, the best metallurgical indexes obtained are obtained when using $40 \mathrm{~g} / \mathrm{t}$ of RVO and $15 \mathrm{~g} / \mathrm{t}$ of MIBC. On the other hand, the use of RVO/PAX mixtures allows the flotation process to be carried out in the absence of foaming agent, achieving even better metallurgical indexes than those obtained with conventional PAX collectors. This phenomenon could be explained by the presence of RVO in the process, which could play an additional role as frother, given its physical and chemical properties. In this aspect, it is necessary to emphasize that the use of mixtures achieves a great performance in collective terms, achieving the highest recovery of all the conditions studied and the highest selectivity with respect to the $\mathrm{Cu}$-Si case, as well as a mass reduction of approximately four times of the feed to the concentrate stream.

\section{Conclusions}

This research proposed to study an RVO as a collector of copper sulfide minerals in the flotation process in seawater in order to contribute to reducing the toxic collector used in minerals processing and to find a different type of application of this waste. Based on the metallurgical analysis, it is possible to note that the RVO collector was more selective for chalcopyrite than PAX but gives a lower recovery. In addition, by analyzing the mixture of both collectors, in the absence of frother, the best results in collective terms and selectivity were obtained. According to these preliminary results, it is possible to conclude that the addition of RVO improved the selectivity of the conventional collector PAX, which is highly collective, in the rougher flotation of copper sulfide minerals in seawater. This could be an interesting opportunity for the industry in order to minimize the costs of the flotation process and generate a lower environmental impact and significant health advantages since it could help to reduce the use of toxic xanthates. However, future research is needed in order to find the best method of addition of the RVO to the process, to study new mixtures with other collectors and to analyze the frother characteristics. In addition, it could be important to understand the effect of the presence of RVO in subproducts as molybdenite.

Author Contributions: Conceptualization, methodology, data curation, visualization, validation, formal analysis, investigation, writing-original draft preparation writing-review and editing, F.A. and L.U. All authors have read and agreed to the published version of the manuscript. 
Funding: This research received no external funding.

Data Availability Statement: The data presented in this study are available on request from the corresponding author.

Acknowledgments: The authors wish to thank the support from the ANID/FONDAP/15130015 project.

Conflicts of Interest: The authors declare not conflict of interest.

\section{References}

1. COCHILCO. Sulfuros Primarios: Desafíos y Oportunidades; COCHILCO: Santiago, Chile, 2017.

2. Rezaei, R. Removal of the residual xanthate from flotation plant tailings using modified bentonite. Miner. Eng. 2018, 119, 1-10. [CrossRef]

3. Li, X.F. Teratogenic toxicity of butyl xanthate to frog embryos. Acta Scient. Circum. 1990, 10, $213-216$.

4. Lam, K.S. Biodegradation of Xanthate by Microbes Isolated from a Tailings Lagoon and a Potential Role for Biofilm and Plant/Microbe Associations. Ph.D. Thesis, Western Sydney University, Penrith, Australia, 1999.

5. Zhao, Y.H.; Xie, M.H.; Luo, X.P. Investigation on removal of xanthate in flotation effluent. Metal Min. 2006, 6, 75-77.

6. Boening, D.W. Aquatic toxicity and environmental fate of xanthates. Miner. Eng. 1998, 50, 65-68.

7. Harris, G.H. Xanthates. In Kirk-Othmer Encyclopedia of Chemical Technology; John Wiley \& Sons: Hoboken, NJ, USA, 2000. [CrossRef]

8. Wang, B.; Peng, Y. The effect of saline water on mineral flotation-A critical review. Miner. Eng. 2014, 66-68, 13-24. [CrossRef]

9. Moreno, P.A.; Aral, H.; Cuevas, J.; Monardes, A.; Adaro, M.; Norgate, T.; Bruckard, W. The use of seawater as process water at Las Luces copper-molybdenum beneficiation plant in Taltal (Chile). Miner. Eng. 2011, 24, 852-858. [CrossRef]

10. Wang, B.; Peng, Y. The behaviour of minerals matter in fine coal flotation using saline water. Fuel 2013, 109, 309-315. [CrossRef]

11. Morales, F. Estudio del Efecto de las Interacciones del Sistema 'agua de mar-cal' en Procesamiento de Minerales. Master's Thesis, Universidad de Chile, Santiago, Chile, 2017.

12. Minería Chilena. Available online: https://www.mch.cl/reportajes/el-combate-contra-la-corrosion/\# (accessed on 15 October 2019).

13. Marulanda, J.; Pérez, D.; Remolina-Millán, A. Resistencia a la corrosión en ambiente salino de un acero al carbono recubierto con aluminio por rociado térmico y pintura poli aspártica. Rev. Ion Investig. Optim. Nuevos Procesos Ing. 2017, 30, $21-31$.

14. Uribe, L. Efecto del Agua de mar en la Recuperación de Minerales de Cobre-Molibdeno por Procesos de Flotación. Ph.D. Thesis, Universidad de Concepción, Concepción, Chile, 2017.

15. Castro, S. Challenges in flotation of Cu-Mo Sulfide ores in seawater. In Water in Mineral Processing; Society for Mining, Metallurgy, and Exploration: Englewood, CO, USA, 2012; pp. 29-40.

16. Laskowski, J.S.; Castro, S.; Ramos, O. Effect of seawater main components on frothability in the flotation of Cu-Mo sulfide ore. Physicochem. Probl. Miner. Process. 2013, 50, 17-29.

17. Williams, C.; Peng, Y.; Dunne, R. Eucalyptus oils as green collectors in gold flotation. Miner. Eng. 2013, 42, 62-67. [CrossRef]

18. Owusu, C. The use of canola oil as an environmentally friendly flotation collector in sulphide mineral processing. Miner. Eng. 2016, 98, 127-136. [CrossRef]

19. Brandao, P.R.G.; Caires, L.G.; Queiroz, D.S.B. Vegetable lipid oil-based collectors in the flotation of apatite ores. Miner. Eng. 1994, 7, 917-925. [CrossRef]

20. Bauer, K.; Greene, M.G.; Di Reber, N.R.; Young, S.K.; Young, T.L. Flotation of Sulfide Minerals with Oils. Australia. Patent WO 2000009268 A1, 24 February 2000.

21. Greene, M.G.; Walton, K.; Dimas, P.A.; Laney, D.G.; Young, S.K.; Young, T.L.; Reber, N.R.; Reber, N.R., Jr. Collectors for Flotation of Molybdenum-Containing Ores. U.S. Patent Application No. 0,145,605A1, 14 June 2012.

22. Benn, F.W.; Dattilo, M.; Cornell, W.L. Flotation of Lead Sulfides Using Rapeseed Oil. U.S. Patent 5,544,760, 13 August 1996.

23. Montalti, M.; Fornasiero, D.; Ralston, J. Ultraviolet-visible spectroscopic study of the kinetics of adsorption of ethyl xanthate on pyrite. J. Colloid Interface Sci. 1991, 143, 440-450. [CrossRef]

24. Gaudin, A.M. Flotation; McGraw-Hill: New York, NY, USA, 1957. 